\title{
Autobiografia e a necessária incompletude das histórias de professores ${ }^{1}$
}

\author{
Autobiography and the necessary incompleteness of teachers' stories
}

\author{
Autobiografía y la necesaria incompletud de las historias de los \\ profesores \\ Janet L. Miller ${ }^{2}$ \\ Columbia University, Teachers College, Professora Emérita \\ https://orcid.org/0000-0001-6701-3883
}

Resumo: 0 artigo é um convite para interrogar meu trabalho sobre autobiografia, gênero e currículo. Em diálogo com a obra de Maxine Greene, em especial com "As formas da infância relembrada", revisito meu interesse pela autobiografia, como gênero e método, na pesquisa educacional. As questões que atraem minha atenção são os desafios que as teorias pós-estrutural, psicanalitica, pós-colonial e queer apresentam à unidade e à coerência do "eu" intacto e plenamente consciente das práticas autobiográficas ocidentais, assim como aos limites de sua representação. Argumento que a autobiografia, como uma forma de investigação educacional, seja considerada também como literatura, assumindo o potencial da literatura imaginativa de interromper, ao invés de reforçar, as versões estáticas e essencializadas de nossos "eus" e do nosso trabalho como educadores. Esse pode, a meu ver, ser o único motivo para usar a autobiografia como uma forma de investigação educacional. Palavras-chave: Currículo. Autobiografia. Formação de professores.

Abstract: This article is an invitation to interrogate my work on autobiography, gender and curriculum. In dialogue with the work of Maxine Greene, especially with "The shapes of childhood recalled", I revisit my interest in autobiography as both genre and method in educational research. The issues that compel my attention are the poststructural, psychoanalytic, postcolonial and queer theory challenges to the unity and coherence of the intact and fully conscious "self" of Western autobiographical practices and

\footnotetext{
0 texto Autobiography and the necessary incompleteness of teachers'stories foi publicado originalmente na obra A Light in Dark Times: Maxine Greene and The Unfinished Conversation, editada por Janet L. Miller e Bill Ayers, em 1998. Em 2005, fez parte da obra Sounds of Silence Breaking: Women, Autobiography, Curriculum, de Janet L Miller, publicada pela Peter Lang. Nesta publicação, a versão sofreu alguns acréscimos de excertos publicados em Biography and Questions of the Private Voice, de 1998, e também parte do livro Sounds of Silence Break, e foi precedida por um interlúdio que apresentava o texto. A tradução que aqui apresentamos segue o formato do texto nesta obra e foi realizada com a permissão da autora. A autora autorizou a publicação da tradução na Roteiro. 0 texto foi traduzido por Paula Lemos (E-mail: paulacdelemos.bio@gmail.com), com revisão técnica de Elizabeth Macedo (E-mail: elizabethmacedo@gmail.com) e Maria Santos (E-mail: santtosmaria.m@gmail.com).

2 Doutora pela The Ohio State University; Mestre pela University of Rochester.
} 
to the limits of its representation. I am arguing that autobiography as one form of educational inquiry be regarded as literature, assuming the potential of imaginative literature to disrupt rather than reinforce static and essentialized versions of our "selves" and our work as educators. This may be, in my opinion, the only reason to use autobiography as a form of educational inquiry.

Key words: Curriculum. Autobiography. Teacher education.

Resumen: El artículo es una invitación a cuestionar mi trabajo sobre autobiografía, género y currículo. En diálogo con la obra de Maxine Greene, especialmente con "Las formas de la infancia recordadas", revisito mi interés por la autobiografía, como género y método, en la investigación educativa. Los temas que me llaman la atención son los desafios que presentan las teorías postestructural, psicoanalítica, poscolonial y queer a la unidad y coherencia del "yo" intacto y plenamente consciente de las prácticas autobiográficas occidentales, asi como los límites de su representación. Sostengo que la autobiografía, como forma de investigación educativa, también se considera literatura, asumiendo el potencial de la literatura imaginativa para interrumpir, en lugar de reforzar, las versiones estáticas y esencializadas de nuestro "yo" y nuestro trabajo como educadores. En mi opinión, ésta puede ser la única razón para utilizar la autobiografía como forma de investigación educativa.

Palabras claves: Currículo. Autobiografía. Formación docente.

Recebido em 11 de janeiro de 2021 Aceito em 18 de fevereiro de 2021

\section{INTERLÚDIO}

Escrevi o texto a seguir para a coletânea que eu e Bill Ayers editamos juntos em 1988, A Light in Dark Times: Maxine Greene and The Unfinished Conversation IUma Luz em tempos escuros: Maxine Greene e uma conversa interminada]. Criei-o, principalmente, como uma ponderação sobre as maneiras pelas quais o trabalho acadêmico de Maxine influenciou profundamente os temas e as questões a que venho me dedicando. Essa era a intenção da coleção editada. Ao atender aos desejos expressos de Maxine, Bill e eu pedimos aos colaboradores que não discutissem ou analisassem os seus escritos em si, mas que ilustrassem, descrevessem, teorizassem maneiras pelas quais temas e conceitos específicos ou abordagens do seu corpo de trabalho único e amplo teriam afetado os trabalhos dos autores.

Foi durante o coffee break, na Conferência de Bergamo, na metade dos anos 90, que Bill me pediu para considerar a possibilidade de editarmos juntos tal coletânea. Eu imediatamente concordei porque eu sabia que Bill Ayers compartilhava do meu amor e admiração por Maxine, assim como por sua ardente dedicação a professores e estudantes, ao ensino sobre e por 
justiça social, e às artes como meio de estimular o que ela chama de "imaginação social". Mas Bill e eu chegamos ao nosso recorte particular do livro de Maxine, como nós pretendíamos chamálo, não por causa do nosso longo relacionamento individual com ela, mas porque ela nos disse, em termos inequívocos, que ela não queria ser apresentada como um ícone. Essa foi a principal razão que ela forneceu para não ir a nenhuma das conferências sobre a Reconceptualização das teorias curriculares, a não ser as bem iniciais. Ela simplesmente não queria ser citada - ou abordada - como se fosse uma figura de proa, uma abstração fixa e completa, ao invés de uma pessoa real que está sempre mudando e se tornando.

Neste texto, abordo a insistência de Maxine em dar ao seu trabalho e à sua vida uma ênfase existencial no ato necessário, ainda que estressante, de escolher constantemente tratar de assuntos profundos. Não se trata, no entanto, apenas de um texto sobre Maxine, razão pela qual ela faz parte do meu livro Sounds of Silence Break ISons da interrupção do silêncio] (MLLER, 2005). Esse livro introduz tensões variadas nos usos e formas da autobiografia na educação, aludindo o sentido de efeitos de construções solidificadas e reificadas de gênero, especialmente de mim mesma como "mulher-professora-acadêmica", que ocupam muitas das minhas investigações ao longo da minha vida acadêmica.

Eu situo o artigo que se segue como um convite para interrogar meu trabalho sobre autobiografia, gênero e currículo. Certamente, ele não é nenhuma afirmação definitiva sobre a investigação autobiográfica, de gênero ou currículo na educação. Em vez disso, este ensaio - complementado com trechos de outra peça publicada em 1998 - destaca preocupações que eu ainda tenho em conta quando escrevo e ensino autobiografia como gênero e método, quando exploro construções atuais e debates sobre gênero e quando situo autobiografia e estudos de gênero como terrenos vitais, ainda que contestados, da teorização curricular e da pesquisa educacional ${ }^{3}$.

\section{AUTOBIOGRAFIA E A NECESSÁRIA INCOMPLETUDE DAS HISTÓRIAS DE PROFESSORES}

\footnotetext{
"Nenhum de nós consegue ver o todo ou cantar o todo. Desde que eu era criança, eu sabia que todas as perspectivas são contingentes, que a imagem de ninguém é completa." Maxine Greene, "The Shapes of Childhood Recalled" IAs formas da infância relembrada]
}

\footnotetext{
Os dois últimos parágrafos foram modificados para que o texto faça sentido como peça isolada, com o acordo da autora.
} 
A primeira vez que li os trabalhos de Maxine Greene, eu estava estudando para o meu mestrado na Universidade de Rochester em 1973 e 1974. Tinha acabado de me divorciar, vivia sozinha numa estranha e fria cidade, e fazia mestrado ao invés de ensinar inglês para os dois últimos anos do ensino médio, como tinha feito nos sete anos anteriores. Desconectada de tudo o que me era familiar, me agarrei aos processos reconhecíveis de ser uma estudante. Sem saber sobre onde ou como eu poderia viver, pelo menos sabia que eu poderia ler e estudar.

Obtive conforto por saber como ser uma estudante, mas fui rapidamente imersa em um trabalho novo, não-familiar e disruptivo. Eu inicialmente li o trabalho de Maxine no contexto que William Pinar, meu orientador acadêmico em Rochester, caracterizou como uma "reconceptualização" emergente do campo curricular estadunidense. Essa reconceptualização, desde o início, mudou a ênfase no campo curricular da preocupação com atividades lineares e sequenciais de projetar e desenvolver o "conteúdo" para o foco na compreensão do currículo abrangendo e examinando dimensões pessoais e políticas da experiência educacional. Mas, como aluna e professora, eu apenas havia conceituado e trabalhado com o currículo escolar de maneiras que Pinar caracterizava como "tradicional" (PINAR, 1975).

Encontrei Maxine pela primeira vez e a ouvi apresentando seus trabalhos acadêmicos em 1973 e 1974 nas primeiras conferências sobre teoria curricular identificadas com a Reconceptualização. Vestida em seu preto Nova York, inclinando-se ao ritmo de suas palavras, olhando periodicamente para o teto enquanto falava, Maxine articulou imperativos pessoais e políticos na conceptualização do currículo como meio pelo qual tomar "o ponto de vista de um estranho em realidade cotidiana" e olhar "inquisitivamente e espantosamente sobre o mundo em que alguém vive." (GREENE, 1973, p. 267). Ah. Talvez essa fosse uma maneira para eu começar a entender o currículo reconceptualizado.

Tais perspectivas informaram meus estudos de graduação em Literatura Inglesa, mas não influenciaram, de modo algum, minha fraca e comportamental preparação como professora na graduação ou minhas experiências como professora efetiva em tempo integral no ensino médio. Lá, fui pressionada a apresentar versões predeterminadas, sequenciais, orientadas por habilidades orientadas e mensuráveis do "inglês" para meus alunos dificilmente maneiras de os encorajar a olhar "inquisitivamente e pensativamente o mundo".

Imediatamente, fui atraída pelas convincentes análises filosóficas e políticas de Maxine Greene que apresentavam o currículo como projeto, como o conceito existencial de sempre "tentar trazer à existência" (SARTRE 1968, p. 91), um eu em relação com o conhecimento, com o mundo. E eu amei seus usos da literatura como meio de engajamento em um projeto 
como esse. Quando eu ensinei inglês no ensino médio durante aqueles sete anos, eu tinha apenas alguns poucos colegas com os quais conversava sobre como evitar as pressões para ensinar a mecânica da gramática e, até mesmo, a literatura como "corpos de conhecimento" fixos e imutáveis e para apresentar esse conhecimento de forma isolada, esquemática e "oficial". Nos escritos de Maxine, encontrei finalmente os imperativos teóricos, filosóficos e políticos para o que havia sido considerado entre alguns de meus colegas como atitudes e perspectivas "subversivas" sobre o ensino. Ao ler e ouvir Maxine, eu não me sentia mais apreensiva ou mesmo culpada por querer que meus alunos olhassem "inquisitiva e pensativamente" seus diversos mundos, sabendo, ao mesmo tempo, que "todas as perspectivas são contingentes, que a imagem de ninguém está completa." (GREENE, 1995, p. 82).

E encontrei conforto nos inúmeros exemplos literários que iluminavam o trabalho de Maxine. Desde minha infância, a literatura me forneceu um meio pelo qual eu podia olhar "com um ponto de vista estranho para a realidade cotidiana" de crescer em um bairro predominantemente branco de classe média trabalhadora da indústria siderúrgica, nas colinas ao sul de Pittsburgh. Mais tarde, a literatura iluminou as maneiras pelas quais as minhas "realidades cotidianas" subsequentes - ensinar em uma pequena cidade industrial nas margens do rio St. Lawrence, no norte do estado de Nova York - foram influenciadas, e até construídas, por contextos econômicos, políticos, discursivos, sociais e culturais entrelaçados e contraditórios nos quais eu vivi e ensinei.

Mas, quando eu primeiro encontrei Maxine e seu trabalho, minha aproximação se deu pelo que era familiar na minha vida pessoal e também no meu trabalho como professora. Eu havia estudado $A$ Peste, de Camus, com meus alunos do último ano do ensino médio, por isso me senti segura de que poderia me associar imediatamente à insistência de Maxine em um "amplo-despertar", como uma forma de vigilância moral e ação contra as pragas do hábito, da passividade, da indiferença e da alienação. Eu também havia ensinado $A$ casa de boneca, de lbsen, e estava lendo 0 despertar, de Kate Chopin, em uma de minhas aulas de pós-graduação - certamente eu poderia continuar a considerar o que, no início dos anos 1970, essas representações literárias da vida das mulheres tinham a ver com a minha própria.

Minhas leituras mais imediatas do trabalho de Maxine Greene, então, refletiram minhas próprias paixões: a literatura e o ensino imaginativos e suas potencialidades para levar indivíduos a ver e agir contra o hábito e a indiferença. Mas como fenomenóloga existencial, Maxine e seu trabalho também me afastaram do familiar e em direção ao mundo. Trabalhando para entender como os encontros com as artes, especialmente encontros com a literatura, poderiam abrir espaços curriculares para uma multiplicidade de realidades, escrevi uma tese, em The Ohio State University, sobre a relação do trabalho de Maxine com os campos da teoria curricular e do ensino de inglês. Maxine se distanciou de qualquer categorização de 
suas intenções e perspectivas, de modo que eu tentei ler e situar seu trabalho de modo contingente, como algo que excede os limites do rótulo "Reconceptualista".

Durante os meados da década de 1970, também comecei a trabalhar autobiograficamente, ao mesmo tempo me debatendo com várias orientações feministas sobre esse modo particular de investigação que contribuiu para a "reconceptualização" do campo curricular nos EUA. Continuei a ser influenciada pelo método autobiográfico Currere, de Pinar (1975) - um método que permite estudar as relações entre o conhecimento acadêmico de cada um e a sua história de vida - bem como pelas teorizações sobre autobiografia de Pinar e Grumet (1976).

Além disso, fui atraída pelos esforços de, durante a década de 1970 e início da década de 1980 nos EUA, teorizar a autobiografia das mulheres com base na "experiência" (JELIINEK, 1980; MASON; GREEN, 1979). Com base nos fundamentos do feminismo de Segunda Onda dos anos 70 (NICHOLSON, 1997), concentrei, inicialmente, minha pesquisa autobiográfica em construções patriarcais internalizadas de identidade e gênero, em questões sobre "ser" e "tornar-se" uma "mulher" que ensina, pesquisa e teoriza em uma profissão dominada por homens. Essas eram questões que Maxine tinha começado a abordar a partir de sua posição como filósofa educacional influenciada pela fenomenologia existencial. Seus usos das análises históricas e da literatura imaginativa para conceituar e interrogar "dilemas", bem como "o trabalho" das mulheres (1978, 1988), como evidência de um projeto pessoal de "sempre se tornar", me deram um impulso e um desafio quando eu comecei minhas explorações feministas.

Mais tarde, me afastei dos princípios do feminismo da Segunda Onda que, juntamente com muitos outros, achei limitativos e excludentes. Esses princípios (1) veem a vida das mulheres como inextricavelmente incorporada no patriarcado entendido como um sistema geral, transcultural e não-histórico de organização social; e (2) afirmam, sem problematizar, a categoria de "mulher" e também um "nós" universal, "mulheres" (SMTH; WATSON, 1998). Ao rejeitar esses princípios da Segunda Onda, comecei a explorar as orientações pós-estruturais e da teoria queer para trabalhar a autobiografia como uma prática historicamente situada e discursivamente flexionada. Tal prática posiciona os sujeitos como irredutivelmente múltiplos, chama a atenção para construções de "identidade" produzidas e sustentadas por normas culturais, e alude à performatividade - a natureza política e provisória da formação de identidade (BUTLER, 1993). 


\section{ENFORMANDO OS EUS}

O ensaio "As formas da infância relembrada", no qual Maxine Greene (1995) "recupera" experiências literárias que foram significativas em vários momentos de sua vida, certamente rompe as noções modernistas de individuos unificados, racionais, coerentes, autônomos e "completos". Ao mesmo tempo, esse trabalho exemplifica maneiras pelas quais a busca pela agência, mesmo diante de construções de identidade provisórias e mutáveis, impulsiona suas rupturas. Além disso, ao detalhar suas várias respostas à literatura imaginativa, Maxine também desafia categorias normativas, singulares e essencialistas, tais como "mulher", nas quais repousam versões da autobiografia que supostamente contam "a história verdadeira de cada um". 0 trabalho de Maxine continua, assim, a informar minhas explorações tanto das tensões quanto dos potenciais dos vários usos e formas da autobiografia como modos de pesquisa e teorização curricular feminista. Ao evocar "as formas da infância lembrada", Maxine explora seu senso da ressonância de várias imagens de obras particulares da literatura e o que essas imagens e histórias "tinham a ver com os padrões que eu estava construindo quando criança, com os horizontes em direção aos quais eu estava estendendo minhas mãos." (GREENE, 1995, p. 80).

Através de suas relembradas respostas à literatura imaginativa, Maxine também examina aspectos de sua "história de vida" como mulher e acadêmica ao recusar qualquer construção definitiva dessa história. Maxine, "como uma aranha, [...] de alguma maneira, [não] cria uma teia exclusivamente a partir das coisas" de seu próprio ser, nem "afirma estar livre das influências modeladoras dos contextos." (GREENE, 1995, p. 74). Em vez disso, ela reconhece a impossibilidade de construir sua história de vida fora de "toda uma variedade de ideologias e práticas discursivas", incluindo aquelas relacionadas a gênero, a relacionamentos fraternos e maternais e a fenômenos políticos e profissionais (GREENE, 1995, p. 74). Ao fazê-lo, ela oferece desafios provocativos a qualquer versão simplista da autobiografia como um "jogo da memória" (GREENE, 1995, p. 77), ou como um esforço meramente autoindulgente, ou como um reforçador de construções já conhecidas ou predeterminadas dos "eus". E, como sempre em seu trabalho, há imperativos politicos associados a sua encenação única de autobiografia:

Se eu puder apresentar as formas e estruturas de um mundo percebido, embora elas tenham sido revestidas com muitos significados racionais ao longo do tempo, acredito que meu próprio passado aparecerá de maneiras alteradas e que minha vida vivida presente - e gostaria de dizer, atuação docente - se tornará mais enraizada, mais pungente e menos suscetivel à racionalização lógica, sem falar na instrumentalidade racional. (GREENE, 1995, p. 77-78). 
Além disso, Maxine argumenta que "as narrativas que enformamos dos materiais de nossas vidas vividas devem, de alguma forma, levar em conta nossas paisagens originais". Nessas paisagens há "um senso de consciência sendo aberto ao comum" e, nelas, talvez possamos "nos reconhecer" para "tomar iniciativas do tipo que relacionam perspectivas a um todo mais ou menos coerente, mesmo que inacabado." (GREENE, 1995, p. 74-75). Agora, eu me debato com a impossibilidade de compreender totalmente nossas "paisagens originais" ou de relacionar diferentes perspectivas em um "todo", mas concordo que é a "incompletude [...] que nos convoca para as tarefas de conhecimento e ação, [...] colocando uma explicação em palavras, combatendo uma praga, buscando lares para os sem-teto, reestruturando escolas desumanas." (GREENE, 1995, p. 74).

Maxine, ao impor sua própria ordem do dia-presente às formas da infância lembrada, fornece vislumbres de contradições, disjunções e ambivalências - a "incompletude" que ela experimenta dentro e em direção a seu "eu" como uma mulher que deseja, ao mesmo tempo, se "fundir e estar fora" (GREENE, 1995, p. 84), como acadêmica que se atreve a fazer filosofia da educação de formas não convencionais e como uma pesquisadora que lê a literatura imaginativa como uma maneira de perturbar e questionar a versão final de qualquer um sobre si mesmo ou sobre o mundo.

Ao mesmo tempo, Maxine gesta possibilidades de agir contra condições injustas e desumanas, mesmo quando os indivíduos enfrentam o "incompleto" e o "todo inacabado" de suas ações, seus conhecimentos, seus "eus" e suas vidas. Entendo que isso significa que, ao reconhecer que tenho a responsabilidade de agir em um mundo injusto e contra ele e ao admitir a possibilidade de que eu "reconheça" um outro com quem realizar tais ações, não estou paralisada pelos limites ou pela "incompletude" de meus "eus" ou por meus compromissos ou por minha incapacidade de "ver o todo ou cantar o todo" (GREENE, 1995, p. 82).

Sou particularmente atraida por este ensaio de Maxine sobre "as formas da infância relembrada" porque ele evoca tensões provocativas no fazer da autobiografia educacional que resiste ao fechamento ou à paralisia em torno de questões de identidade e agência. E, como sempre, sou atraída pelos encontros de Maxine com a literatura imaginativa como um meio de romper a obviedade aceita do "eu" de cada um ou de seu mundo.

\section{AUTOBIOGRAFIA E O EU INCOMPLETO}

Minha leitura de "As formas da infância relembrada", de Maxine, reflete meu interesse contínuo pela autobiografia como gênero e método na pesquisa educacional. Questões que agora atraem minha atenção são os desafios que as teorias pós-estrutural, 
psicanalítica, pós-colonial e queer apresentam à unidade e à coerência do "eu" intacto e plenamente consciente das práticas autobiográficas ocidentais, assim como aos limites de sua representação. Chamando atenção para o discurso como uma força constitutiva, por exemplo, Shoshana Felman (1993, p. 156-157) observa, "Não podemos simplesmente 'escrever' nossas histórias nem decidir escrever 'novas' histórias [...] porque a decisão de reescrevê-las não é simplesmente externa à linguagem que involuntariamente nos escreve." Aqui elaboro um pouco com uma seção de um artigo meu de 1998, Biografia, Educação e Questões da Voz Privada (MLLLER, 2005, p. 229-230):

0 argumento de Felman leva em consideração [...] questões de poder, linguagem e subjetividade que circulam entre o biógrafo e sujeito, $\circ$ autobiógrafo e o "eu", o pesquisador e o pesquisado. Essas perspectivas levam em conta o momento pós-moderno como, nas palavras de Marshall (1992), "uma consciência de estar - dentro de uma maneira de pensar [...] de ser - dentro, primeiro, de uma língua e, segundo, de um contexto histórico, social, cultural particular" (p. 3). Essas perspectivas, portanto, chamam a atenção para a linguagem como fator constituinte das separações artificiais, ordenações hierárquicas e construções essencialistas de público e privado, teoria e prática, eu e outro. Considere a formulação de Weedon (1987) aqui: A linguagem é o lugar onde formas efetivas e possiveis de organização social e suas prováveis consequências sociais e politicas são definidas e contestadas. No entanto, é também o local onde nosso senso de nós mesmos, nossa subjetividade, é construída. A suposição de que a subjetividade é construída implica que ela não é inata, não é determinada geneticamente, mas produzida socialmente. A subjetividade é produzida em toda uma gama de práticas discursivas - econômicas, sociais e politicas cujos significados são um local constante de luta pelo poder. A linguagem não é a expressão de uma individualidade única; ela constrói a subjetividade do individuo de maneiras socialmente específicas. [...] Diferentemente do humanismo, que implica um sujeito consciente, conhecedor, unificado e racional, o pós-estruturalismo teoriza a subjetividade como um local de não-unidade e conflito, central para o processo de mudança política e para preservar o status quo (p. 21).

Os educadores que desejam usar a biografia, a autobiografia e a narrativa como formas de investigação na formação de professores e na pesquisa do currículo que possam desafiar a atual padronização desenfreada e medição da vida educacional de alunos e professores devem prestar atenção às implicações geradas por essas perspectivas. Professores e pesquisadores devem abordar questões de construção de identidade, subjetividade e relações de poder que circulam pela linguagem e, também, pela interação humana. Essas questões, no mínimo, chamam a atenção para o calorde fato, o calor gerado pela imprevisibilidade, pelas multiplicidades, pelas confusões e pelo incognoscível em uma vida educacional.

Ao mesmo tempo, preocupadas com questões de ação e ação, muitas teóricas feministas da autobiografia estão discutindo como conceituar "eu" e "mulher", não como permanentemente essencializados ou naturalizados através da linguagem e cultura, mas 
sim como locais de crítica cultural e mudança social. Ao estruturar uma teoria feminista da autorrepresentação das mulheres, Leigh Gilmore (1994), por exemplo, enfatiza a escrita de "identidades" múltiplas, experimentais, contraditórias como um meio de localizar o autobiográfico como um ponto de resistência. Ela enquadra o "eu" como situado simultaneamente em múltiplas construções de identidade e argumenta que a autobiografia pode demonstrar

como as identidades de gênero são especificadas nas identidades culturais, como as identidades raciais são sexualizadas, como as identidades étnicas são generificadas e como as identidades sexuais são influenciadas pela classe, [...] como o "eu" muda nesses lugares e como o poder é distribuído. (GILMORE, 1994, p. 184).

As categorias de identidade nunca são meramente descritivas, mas sempre normativas e, como tais, excludentes. Isso não quer dizer que o termo "mulheres" não deva ser usado, ou que devemos anunciar a morte da categoria. Pelo contrário, se o feminismo pressupõe que "mulheres" designa um campo indesignável de diferenças, que não pode ser totalizado ou resumido por uma categoria de identidade descritiva, então o próprio termo se torna um local de permanente abertura e ressignificação.

\section{5 “HISTÓRIAS DOS PROFESSORES” E IDENTIDADES}

Considerar o trabalho de Gilmore e Butler me obriga a perguntar: onde está a "permanente abertura e a resignificabilidade" da categoria identitária "professor" nas muitas versões das "histórias dos professores" que constituem um dos usos mais visíveis da autobiografia e da investigação narrativa no campo da educação, em geral, e da formação de professores, em particular? William Pinar e Madeleine Grumet (1976), em seu trabalho inovador sobre a autobiografia como uma forma de teorização curricular, chamaram a atenção para a necessidade de prestar, de múltiplas formas, contas de si e de experiências na educação, a fim de "cultivar nossa capacidade de ver através de formas exteriores, a explicação habitual das coisas." (PINAR, 1988, p. 149). Essa multiplicidade "fragmenta o dogmatismo de uma única história." (GRUMET, 1991, p. 72).

Mas, considerando as precauções de Butler, Gilmore e Felman, entre outros, creio que análises dessas múltiplas formas são necessárias para discernir maneiras pelas 
quais elas não são "simplesmente externas à linguagem que involuntariamente nos escreve". Assim, mesmo múltiplas versões do "eu" ou de histórias precisam ser examinadas como representativas de construções sociais normativas e historicamente específicas de "raça", "gênero", "etnia", "identidade sexual" ou da categoria de identidade "professor", por exemplo, que são materializadas dentro das práticas discursivas educacionais atuais que enquadram (e constrangem) nossas reescritas.

No entanto, nos últimos anos, construções de identidade não problemáticas de "professor", assim como de "histórias de professores", proliferaram na literatura educacional dos EUA. Elas geralmente assumem uma versão singular, autoritária e completa (como em "professor capacitado" ou "praticante reflexivo") de eu, identidade, experiência, voz e história. Essas "histórias dos professores", geralmente, são acompanhadas de demandas de possibilidades transformadoras da reflexão, do autobiográfico, da narrativa como formas de pesquisa sobre e de professores. Em muitos programas de formação de professores, os professores são incentivados a contar suas investigações sobre questões e problemas com os alunos em suas salas de aula ou em suas práticas pedagógicas e curriculares. Espera-se que esses professores escrevam traçados e reflexões autobiográficas sobre as fontes, as mudanças e as perguntas acerca de suas suposições, expectativas e ações como professores. E muitos formadores incentivam esse trabalho dizendo aos professores "apenas conte sua história".

Algo está faltando neste convite. Uma dificuldade surge quando autobiografias, narrativas ou histórias sobre educação são contadas ou escritas como unitárias e transparentes. Elas acabam, por exemplo, sendo usadas como evidência de "progresso" ou "sucesso" da reforma da escola, "para que o tecido da narrativa pareça uniforme, fiado como uma peça completa. 0 efeito é mágico - o eu parece orgânico, o presente surge como a soma total do passado e o passado como um preditor preciso do futuro." (BENSTOCK, 1991, p. 10).

Além disso, essas "histórias de professores", com frequência, oferecem relatos não problemáticos do que é considerado a "realidade" transparente, linear e autorizada das "experiências" dos professores. E as "identidades dos professores" nessas histórias geralmente são desenhadas como unitárias, de sujeitos plenamente conscientes, universais, completos e não contraditórios - dificilmente lugares de "abertura permanente e ressignificabilidade". É claro que essas histórias e identidades estão fundamentadas nas noções modernistas do indivíduo iluminista em contato com as quais muitos de nós, nos Estados Unidos, crescemos. Nelas, a narrativa dominante na educação inclui a crença de que tanto o progresso acadêmico, quanto o desenvolvimento "pessoal" dos alunos é linear, sequencial e mensurável. Ou seja, muitos de nós crescemos em meio a normas culturais ocidentais que reforçavam as noções de um "eu" [l] que era sempre um "eu acessível", completamente aberto à observação, à análise racional e até à "correção" por si [self] e 
pelos outros, ao invés de um "eu" [l] performativo, que se torna um ser provisório por meio da construção social da identidade de gênero, por exemplo (BUTLER, 1993).

Da mesma forma, muitos de nós estamos fundamentados em uma noção de "experiência" que falha em questionar como nossas noções de experiência significativa também são produzidas social e discursivamente, mesmo quando também reconhecemos que existem experiências humanas fora dos discursos narrativos - memórias sensoriais de imagens e eventos, sentimentos, desejos. Uma noção humanista ocidental de experiência não concebe os indivíduos como sujeitos constituídos pela experiência, nem considera como nos conhecemos a nós mesmos por intermédio de regimes discursivos, regimes que servem como registros culturais (em mudança) para o que conta como experiência e para quem conta como um sujeito que experimenta (FOUCAULT, 1980; SCOTT, 1991).

Também não é de surpreender que muitos educadores abordem os usos pedagógicos e de pesquisa da autobiografia assumindo que existem correspondências simples e transparentes entre "identidade", "voz", "experiência" e "memória". Tais formas de autobiografia proliferarão no campo da educação, enquanto se continuar a enfatizar o presente como somatório totalizante do passado e o passado for visto como preditor do futuro lem termos, por exemplo, de desempenho do aluno como "evidência" de eficácia do professor].

Uma dificuldade que vejo nas versões iluministas de "professor" e de suas "histórias", portanto, é que muitas não exploram e teorizam contextos e influências sociais ou culturais, incluindo discursos educacionais historicamente específicos, sobre construções do "eus" que têm "experiências". Tais "narrativas descosturadas" geralmente não analisam o trabalho "que a linguagem faz para limitar, moldar e tornar possível um mundo ou outro." (DAVIES, 1993, p. Xviii). Como resultado, versões unificadas, singulares e essencializadas do "eu", da "experiência", do "outro" e da "voz" continuam a ser produzidas no campo da educação, em geral, e nas estratégias pedagógicas e construções do currículo, em particular.

Considere, por exemplo, concepções de "voz" e "eu" no trabalho daqueles conhecidos como teóricos expressionistas da composição dentro da disciplina em que trabalho desde 1966 - o inglês. Mais uma vez, da minha peça biográfica de 1998 (MLLER, 2005, p. 231-232):

Por um lado, os chamados "expressionistas" na teoria da composição defendem uma noção de voz como inerente e emergente no indivíduo. Os expressionistas muitas vezes incentivam o desenvolvimento da "voz autêntica" na escrita do aluno e estimulam formas de escrita pessoal, incluindo a biográfica e a autobiográfica, como meio de explorar uma voz que é fiel ao eu do aluno. 
Outros teóricos, como Klaus (1994), por exemplo, trabalhando com perspectivas pós-modernas que desafiam qualquer noção essencialista de um verdadeiro eu ou de uma voz verdadeira, tentam mostrar como uma concepção de voz autêntica evita tanto circulações histórica e socialmente localizadas de poder quanto $\mathrm{o}$ inconsciente como forças poderosas que mediam quem pode falar:

Tais expressões como "ter a própria voz" ou "ter uma voz autêntica" ou "ter uma voz pessoal distinta" ou "ter o imediatismo de uma voz real" pressupõe uma conexão tão íntima como para implicar que a voz é uma expressão e uma reflexão totalmente autêntica do eu. A forma gramaticalmente singular de tais expressões também tende a sugerir que a voz é singular, não apenas no sentido de ser distintiva ou única, mas também no sentido de ser uma entidade isolada e unificada em si e por ela mesma (p. 114).

Bergland (1994) discute dificuldades adicionais de equiparar a voz a uma versão essencializada do "eu": "Sugiro que precisamos questionar qualquer relação fácil entre o discurso e o sujeito falante, particularmente a suposição de que a experiência produz uma voz: que, por exemplo, ser mulher significa falar na voz da mulher" (p. 134).

Uma maneira de questionar as relações entre discurso, poder e sujeito falante é investigar as consequências de até mesmo categorizar as multiplicidades e complexidades de uma vida como sendo vivida em um binário rígido de voz pública e privada [...] Em vez disso, formas narrativas de investigação educacional autobiográficas, biográficas, poderiam apontar maneiras pelas quais as identidades e vozes de nosso educador nunca são apenas - ou mesmo - públicas ou privadas. Essas formas de investigação podem demonstrar que as vozes nunca são apenas a descoberta esperada de algo pré-existente, nunca são fixas e imutáveis, nunca são facilmente separadas nos reinos distintos e "naturalmente" existentes do público e do privado, nunca imunes a condições sociais ou históricas específicas.

Assim, trabalhos autobiográficos, biográficos e narrativos que apontam para $\circ$ fluxo de identidades construidas, bem como para $\circ$ incognoscivel na "voz" e no "eu", podem ajudar os educadores a resistir a uma versão definitiva e mensurável do aluno ou professor de sucesso, por exemplo. Tais concepções podem ajudar os educadores a continuar desafiando prescrições fáceis sobre gerenciamento, organização e filosofias em sala de aula que garantam que a voz de cada um seja ouvida, ou que o eu de cada um, seja realizado.

Portanto, penso que não é mais possível participar de investigações autobiográficas, biográficas ou narrativas sem fazer perguntas sobre como é problemático que elas sejam usadas como uma memória "factual" de eventos em sala de aula - ou como um meio para encontrar, refletir, melhorar ou celebrar um "eu" completo e inteiro. Um objetivo da autobiografia, como conceituado por Felman (1993), por exemplo, é criar, usar e explorar leituras e escritos de autobiografia que reconheçam sua própria construção social e condicionamento cultural e que, simultaneamente, chamem a atenção para interpretações sempre incompletas, sempre presas à repressão, sempre intermináveis. De fato, nós, educadores, deveríamos reconhecer construções de nossos "eus" como mediados por discursos, contextos culturais e pelo inconsciente. Dessa forma, o uso da autobiografia, como uma forma de pesquisa educacional, 
poderia e necessitaria se mover para além do simplista "contar histórias dos professores" como um fim em si mesmo.

A autobiografia também não deveria ser usada apenas para adicionar "histórias de professores" à pesquisa e à literatura educacional já estabelecidas. A autobiografia, seja na forma de "histórias de professores" seja como análise dos filtros através dos quais, professores e pesquisadores, percebemos nosso trabalho, deve se mover por enquadramentos tradicionais de situações e questões educacionais - e além deles - para "nos levar a um lugar a que, caso contrário, não poderíamos chegar." (BEHAR, 1996, p. 14).

Tais enquadramentos tradicionais, com frequência, incentivaram os professores a resolver discrepâncias entre teoria e prática, entre versões concorrentes de suas formas de ensinar e de seus eus pessoais, ou entre as metas e objetivos das políticas para a escola e as suas formas de dar-lhes vida. Em vez de encontrar "contradições, lacunas, perspectivas a partir da margem e do centro [...] um campo de multiplicidades" (GREENE, 1997, p. 391), que exige a reconsideração e a recriação do "eu" e das normalizações culturais e sociais desse eu, muitos usos da autobiografia no campo da educação incentivaram a criação e o compartilhamento de "histórias de professores" que simplesmente reforçam versões fixas, predeterminadas e resolvidas de nós mesmos e do trabalho. Diferentemente da literatura imaginativa ou de outras formas de arte nas quais, como Maxine Greene nos lembra, "não há um ou outro nítido, nem verdade nem resolução, [...] nenhuma conclusão firme" (GREENE, 1997, p. 391), tais anotações autobiográficas fixas fecham, em vez de abrir, o potencial para reconfigurar o "eu" e o "outro".

Agora, não estou argumentando que a autobiografia como uma forma de investigação educacional seja considerada apenas literatura. No entanto, quero considerar o que poderia acontecer com as formas e os propósitos da autobiografia na educação, se eles assumissem o potencial da literatura imaginativa de interromper, ao invés de reforçar, as versões estáticas e essencializadas de nossos "eus" e nosso trabalho como educadores. De fato, esse pode ser o único motivo para usar a autobiografia como uma forma de investigação educacional. Assim como os encontros informados com a literatura podem levar ao que Maxine chama de "uma surpreendente familiarização com o comum", também a autobiografia pode pôr em questão tanto a noção de um eu "verdadeiro", estável e coerente quanto de scripts culturais para esse eu (GREENE, 1995, p. 4). De fato, a autobiografia como prática de pesquisa educacional pode se tornar um "local de permanente abertura e ressignificação." (BUTLER, 1992).

Tais desafios ao normativo, ao comum, ao garantido podem levar a "reconceber", "revisualizar" e "revisar os termos" da vida de uma pessoa (GREENE, 1995, p. 5). Maxine mostra como essa "des-familiarização" e "revisão" podem ampliar nossas capacidades "para inventar visões do que deveria ser e do que poderia ser em nossa sociedade imperfeita, nas ruas 
onde moramos, em nossas escolas." (GREENE, 1995, p. 5). Este é um dos desafios, acredito, de trabalhar com e em pesquisa autobiográfica em contextos educacionais. "Contar a sua história ou a minha história", sem desafiar nenhuma das linguagens "que involuntariamente nos escrevem" ou o eu como singular, unificado, cronológico e coerente, é manter o status quo. É reinscrever situações e identidades já conhecidas como fixas, imutáveis, presas a concepções normalizadas, e portanto excludentes, do quê e de quem é possível.

Em vez disso, abordar o "eu" e as investigações do "eu" ou da "mulher" ou da "professora", por exemplo, como "locais de abertura e ressignificação permanentes" potencializa o acesso e a criação de novos modos de falar e escrever formas de existência obscuras, desconhecidas ou simplesmente impensáveis quando uma história centrada de autoconhecimento é substituída por outra. Mudar o que significa "ser" ou "tornar-se" professor, aluno ou pesquisador não pode acontecer, simplesmente, "contando minha história ou sua história", se essa história repetir ou reinscrever categorias de identidade já normalizadas e descritivas, como "mulher", "homem", "estudante", "pesquisador" ou "professor".

Reconstituir o mundo de maneiras significativas e necessárias exige que nós, pesquisadores educacionais e teóricos do currículo, pressuponhamos que categorias como professor, pesquisador e aluno possam apontar para "campos indesignáveis de diferenças". Mais que isso, esse professor, pesquisador e aluno não pode e não deve ser "totalizado ou resumido" por exortações não problematizadas a "contar nossas histórias". Novamente, trazendo de meu artigo biográfico:

\footnotetext{
Numa época em que tantas pesquisas educacionais e de formação de professores se concentram em metas e veem o ensino como sistema de entrega de "resultados" mensuráveis e previsíveis, a autobiografia, a biografia e a narrativa - como práticas educacionais e também como metodologia - geram material e processos que nós, educadores, podemos usar para desalojar noções unitárias, tanto de nós mesmos e de nossas vozes quanto dos sistemas prescritivos de ensino e aprendizagem. Esse trabalho também poderia nos permitir reconhecer que os processos de ensino e aprendizagem sempre interrogam o desconhecido - ou seja, o significativo desconhecido. (MLLLER, 2005, p. 234).
}

\section{AUTOBIOGRAFIA EM AÇÃO}

Quero, então, considerar o uso da autobiografia na investigação educacional que força a abertura de categorias de identidade que ainda enquadram, em grande medida, como o ensino, a aprendizagem e o currículo são conceituados e vividos - categorias como "deficiência de aprendizagem", “em risco", "talentoso", "professora no feminino", por exemplo. 
A autobiografia como uma prática educacional pode construir essas categorias como permanentemente abertas, às vezes desconhecidas e, portanto, como campos de diferenças indesignáveis. Tais campos indesignáveis podem, depois, ser lidos a partir da perspectiva transcultural de suas diferenças e das interações entre diferentes linguagens e culturas de modo a se fazerem disponíveis como lugares constantemente ressignificados em nome e em prol de projetos sociais e políticos específicos (FELMAN, 1993).

Essas são as tensões com as quais estou trabalhando agora, em minhas próprias tentativas de "fazer" da autobiografia uma forma de investigação educacional. E, como sempre, o trabalho acadêmico de Maxine me provoca a fazer minhas próprias perguntas e a trilhar as tensões que descrevi ao longo deste texto. Não que eu pudesse chegar a qualquer resolução final e completa. De jeito nenhum. Em vez disso, sigo lutando por maneiras de construir e usar a autobiografia na investigação educacional que não reforcem o que, às vezes, parece ser o desejo coletivo de "conhecer, definir e resumir" (BENSTOCK, 1991, p. 5) meu "eu" ou as práticas tanto da educação quanto da autobiografia. Nisso, lido, especialmente, com as tensões geradas pelo "status irredutivelmente complexo e paradoxal da identidade na política feminista e na escrita autobiográfica.” (MARTIN, 1988, p. 103).

Ao mesmo tempo, guardo ainda o desejo "tomar iniciativas" ao reconhecer que é "a incompletude que nos convoca para as tarefas de conhecimento e ação". Que projetos políticos eu - e os pesquisadores de currículo, os formadores de professores e os professores de sala de aula - posso construir ao usar a autobiografia recusando o fechamento e reconhecendo a construção e reconstrução da experiência e das identidades como interpretativas? Ou seja, sujeita às convenções interpretativas disponíveis para nós e aos significados e identidades que nos são impostos pelos seus usos contínuos na cultura e na linguagem (FELMAN, 1993). Como podemos construir nossas "histórias de professores" de maneiras que falhem a se ajustar às normas impostas socialmente que cercam a vida de nossos educadores? Tais "falhas" sinalizam a "possibilidade de uma variação" das "regras que governam a identidade inteligivel". E, com essas "falhas", vêm as reconfigurações ou mudanças de identidades (BUTLER, 1990, p. 145).

Tais concepções de autobiografia apontam para o "contar histórias" e para as construções de "eus" nessas histórias como processos intermináveis, complexos, condicionados culturalmente e linguisticamente. É para tais complexidades, assim como para as possibilidades de agência, mesmo diante da "incompletude", que os usos da autobiografia feitos por Maxine em "As formas da infância rememoradas" apontam.

Pois é, como Maxine Greene (1995, p. 74) sempre me lembra, é nossa "incompletude - a questão em aberto, talvez - que nos convoca para as tarefas de conhecimento e ação." A visão da promessa de Maxine, a ser encontrada na "incompletude", certamente indica formas de investigação autobiográfica que desafiam qualquer noção fixa ou pré-determinada 
de quem se "é" ou se "poderia ser". Mas, mais do que isso, os compromissos de Maxine com o constante "tornar-se", seu encanto pela incognoscibilidade do "eu" e da vida, seu desejo de estar ligada a pessoas, cujos projetos de vida são "combater uma praga, procurar lares para os sem-teto e reestruturar escolas desumanas" - todos esses aspectos de sua "incompletude" que, ao mesmo tempo, construíram uma vida que de fato fez a diferença.

\section{REFERÊNCIAS}

BEHAR, R. The vulnerable observer: anthropology that breaks your heart. Boston: Beacon Press, 1996.

BENSTOCK, S. The female self-engendered: autobiographical writing and theories of selfhood. Women's Studies, v. 20, p. 5-14, 1991. D0l: https://doi.org/10.1080/00497878.1991.9978885.

BERGLAND, B. Postmodernism and the autobiographical subject. In: ASHLEY, K.; GILMORE, L.; PETERS, G. (org.). Autobiography and postmodernism. Amherst: The University of Massachusetts Press, 1994. p. 130-166.

BUTLER, J. Bodies that matter: on the discursive limits of "sex". New York: Routledge, 1993.

BUTLER, J. Contingent foundations: feminism and the question of "post-modernism". In: BUTLER, J.; SCOTT, J. W. (org.). Feminists theorize the political. New York: Routledge, 1992. p. 3-21.

BUTLER, J. Gender trouble: feminism and the subversion of identity. New York: Routledge, 1990.

DAVIES, B. Shards of glass: children reading and writing beyond gendered identities. Cresskill, NJ: Hampton Press, 1993.

FELMAN, S. What does a woman want? Reading and sexual difference. Baltimore, MD: The Johns Hopkins University Press, 1993.

FOUCAULT, M. Power/knowledge: selected interviews and other writings 1972-1977. New York: Pantheon Book, 1980.

GILMORE, L. Autobiographics: a feminist theory of women's self-representation. Ithaca, NY: Cornell University Press, 1994.

GREENE, M. Metaphors and multiplex: representation, the arts and history. Phi Delta Kappan, v. 78, n. 5, p. 387-394, 1997.

GREENE, M. Releasing the imagination: essays on education, the arts and social change. San Francisco, CA: Jossey-Bass, 1995. 
GREENE, M. Teacher as a stranger: educational philosophy for the modern age. Belmont, CA: Wadsworth, 1973.

GRUMET, M. The politics of personal knowledge. In: WITHERELL, C.; NODDINGS, N. (org.). Stories lives tell: narrative and dialogue in education. New York, NY: Teachers College Press, 1991. p. 67-77.

JELINEK, E. C. Women's autobiography: essays in criticism. Bloomington: Indiana University Press, 1980.

KLAUS, C. H. The chameleon "l": On voice and personality in the personal essay. In: YANCEY, K. B. (org.). Voices on voice: perspectives, definitions, inquiry. Urbana, IL: National Council of Teachers of English, 1994. p. १1१-१२९.

MARSHALL, B. Teaching the postmodern: fiction and theory. New York: Routledge, 1992.

MARTIN, B. Lesbian identity and autobiographical difference. In: BROKSKI, B.; SCHENCK, C. (org.). Life/lines: theorizing women's autobiography. Ithaca, NY: Cornell University Press, 1988. p. 77-103.

MASON, M. G.; GREEN, C. H. Journeys: autobiographical writings by women. Boston: G. K. Hall, 1979.

MLLER, J. L. Sounds of silence breaking: women, autobiography, curriculum. New York: Peter Lang, 2005.

NICHOLSON, L. J. The second wave: a reader in feminist theories. New York: Routledge, 1997.

PINAR, W. F. Contemporary curriculum discourses. Scottsdale, AZ: Gorsuch Scarisbrick Publishers, 1988.

PINAR, W. F.; GRUMET, M. R. Toward a poor curriculum. Dubuque, IA: Kendall/Hunt, 1976.

PINAR, W. F. Search for a method. In: PINAR, W. F. (org.). Curriculum theorizing: the reconceptualists. Berkeley, CA: McCutchan, 1975. p. 415-424.

SARTRE, J.-P. Search for a method. New York: Vintage Books, 1968.

SCOTT, J. The evidence of experience. Critical Inquiry, v. 178, n. 3, p. 773-797, 1991.

SMITH, S.; WATSON, J. Women, autobiography, theory: a reader. Madison: University of Wisconsin Press, 1998.

WEEDON, C. Feminist practice and poststructuralist theory. New York: Basil Blackwell, 1987.

Endereço para correspondência: 525 West 120th Street, New York, NY 10027, United States of America; jm1397@tc.columbia.edu 